\title{
BMJ Open Patient-driven innovations reported in peer-reviewed journals: a scoping review
}

\author{
Maria Reinius (D) , ${ }^{2}$ Pamela Mazzocato (i) , ${ }^{1}$ Sara Riggare (D) , ${ }^{2}$ Ami Bylund (D) , \\ Hanna Jansson (D) , ${ }^{1}$ John Øvretveit (D) , ${ }^{1,3}$ Carl Savage (D) , \\ Carolina Wannheden (D) , ${ }^{1}$ Henna Hasson (D) ${ }^{1,4}$
}

To cite: Reinius M, Mazzocato $P$, Riggare S, et al. Patientdriven innovations reported in peer-reviewed journals: a scoping review. BMJ Open 2022;12:e053735. doi:10.1136/ bmjopen-2021-053735

- Prepublication history and additional supplemental material for this paper are available online. To view these files, please visit the journal online (http://dx.doi.org/10.1136/ bmjopen-2021-053735).

Received 24 May 2021 Accepted 03 December 2021

Check for updates

(c) Author(s) (or their employer(s)) 2022. Re-use permitted under CC BY-NC. No commercial re-use. See rights and permissions. Published by BMJ.

${ }^{1}$ Department of Learning, Informatics, Management and Ethics, Medical Management Centre, Karolinska Institutet, Stockholm, Sweden

${ }^{2}$ Department of Women's and Children's Health, Healthcare Sciences and E-Health, Uppsala University, Uppsala, Sweden

${ }^{3}$ Department of Research Development and Education, Region Stockholm, Stockholm, Sweden

${ }^{4}$ Unit for Implementation and Evaluation, Center for

Epidemiology and Community

Medicine, Region Stockholm,

Stockholm, Sweden

Correspondence to

Dr Maria Reinius;

maria.reinius@ki.se

\section{ABSTRACT}

Background Awareness of patients' innovative capabilities is increasing, but there is limited knowledge regarding the extent and nature of patient-driven innovations in the peer-reviewed literature.

Objectives The objective of the review was to answer the question: what is the nature and extent of patient-driven innovations published in peer-reviewed scientific journals? Eligibility criteria We used a broad definition of innovation to allow for a comprehensive review of different types of innovations and a narrow definition of 'patient driven' to focus on the role of patients and/or family caregivers. The search was limited to years 2008-2020. Sources of evidence Four electronic databases (Medline (Ovid), Web of Science Core Collection, PsycINFO (Ovid) and Cinahl (Ebsco)) were searched in December 2020 for publications describing patient-driven innovations and complemented with snowball strategies.

Charting methods Data from the included articles were extracted and categorised inductively.

Results A total of 96 articles on 20 patient-driven innovations were included. The number of publications increased over time, with $69 \%$ of the articles published between 2016 and 2020. Author affiliations were exclusively in high income countries with $56 \%$ of first authors in North America and 36\% in European countries. Among the 20 innovations reported, 'Do-It-Yourself Artificial Pancreas System ' and the online health network 'PatientsLikeMe', were the subject of half of the articles. Conclusions Peer-reviewed publications on patientdriven innovations are increasing and we see an important opportunity for researchers and clinicians to support patient innovators' research while being mindful of taking over the work of the innovators themselves.

\section{BACKGROUND}

Traditionally, patients have been considered as passive recipients of medical care, merely 'buying' and consuming the services and products that experts (eg, researchers, healthcare professionals, 'medical producers') have created. ${ }^{1}$ However, healthcare providers are increasingly regarding patients as experts in their own conditions, involving them and their family caregivers as active participants
Strengths and limitations of this study

- To our knowledge, this study is the first attempt to perform a comprehensive review of what has been published in peer-reviewed journals about patientdriven innovations.

- The review had a systematic approach in searching four large databases, complemented with snowball sampling.

- Patient-driven innovations are not always labelled in the research as patient-driven innovations and as such, despite the methods used including snowball sampling, the result is likely an under-representation of research of patient driven innovations.

- The study contributes to concepts and operational definitions related to patient innovations, pointing out the result of using an inclusive and broad definition of innovation and a narrow definition of what is meant by patient driven.

in care..$^{2-4}$ Although most policies promote a more active patient role in care, research has found that in reality, patients' role remains limited. ${ }^{56}$ Patients repeatedly report having too little influence over their care while their needs remain unmet in the current healthcare systems. $^{78}$

Many patients want to play a greater role in decisions about their care, to perform more effective self-care, and to engage in improving healthcare systems. ${ }^{3}{ }^{4}$ For example, patient innovators take part in the development and spread of patient-driven innovations. ${ }^{9-11}$ The Patient Innovation website (www.patient-innovation.com), which was created to collect innovations by patients and/or family caregivers, lists over 1200 innovations. This gives an indication of significant activity by patients and their family caregivers driving health innovations, often independently of the health system. Patient innovators have been defined as "patients or their nonprofessional caregivers (eg, parents and family members), who modify or develop a treatment, a 
technical aid product, or a medical device to cope with a health condition'. ${ }^{7}$ Although the awareness of patients' innovation capacity is increasing, there is still limited knowledge regarding the extent and nature of patientdriven innovations in the peer-reviewed literature. ${ }^{712} \mathrm{In}$ the discussion section of this paper, we consider possible explanations for this. The objective of the review was to answer the following research question: What is the nature and extent of patient-driven innovations published in peer-reviewed scientific journals?

\section{METHOD \\ Design}

A scoping review method was chosen as the most appropriate for the objective of the study because our initial investigations revealed a diverse range of types of studies and publications, and the method is recommended as useful when examining emerging areas of research. ${ }^{13}$ It was performed according to the five-stage framework proposed by Arksey and O'Malley ${ }^{13}$ and is reported according to the Preferred Reporting Items for Systematic Reviews and Meta-Analyses Extension for Scoping Reviews (PRISMA) Checklist ${ }^{14}$ (online supplemental appendix 1). Critical appraisals of articles were not performed since the aim was to explore the extent and nature of patientdriven innovations, not assess the quality of these. The review does not follow a preregistered protocol.

\section{Definition of key concepts}

To find a shared understanding of the concept 'patientdriven innovation', the research team performed a concept analysis inspired by Walker and Avant. ${ }^{15}$ The concept analysis was performed in a collaborative workshop with patient innovators and researchers where we used key articles to identify model cases of patientdriven innovation, and borderline cases, related cases and contrary cases. Using the concept analysis method, the team agreed to define 'innovation' based on the WHO definition of health innovation as 'an innovation that identifies new or improved health policies, systems, products and technologies, or services and delivery methods that improve people's health and well-being. The innovation aims to add value in the form of improved efficiency, effectiveness, quality, sustainability, safety and/or affordability. The innovation can be preventive, promotive, curative, rehabilitative, assistive and/or palliative care.' The other part of the concept was 'patient driven' that we agreed consisted of two parts and was defined by: (1) The innovation is user driven, meaning that it is both initiated and driven (in development, implementation, etc) by patients and/or family caregivers and (2) The innovation responds to one or more unmet needs of the innovator. Unmet needs are defined by the innovator. This provided a definition broad enough to allow for a comprehensive review of the nature of patient-driven innovations but limited 'patient driven' to focus on the role of patients and/or family caregivers (see table 1 ).

\section{Eligibility criteria}

Eligibility criteria are presented in table 1 . We included studies published in peer-reviewed journals (publication years 2008-2020) that covered health innovations initiated and driven by patients and/or family caregivers (hereafter referred to as patient-driven innovations, as defined in table 1, point 4.1-4.3.). Review articles were used to identify original articles, and review articles that

Table 1 Eligibility criteria for inclusion

\begin{tabular}{ll}
\hline Inclusion criteria & Exclusion criteria \\
\hline 1. English language & Other language than English \\
2. Published between January 2008 and December 2020 & Published earlier than 2008 or later than 2020 \\
3. Published in a peer-reviewed journal & Not published in peer-review journal \\
$\begin{array}{ll}\text { 4. Reporting on patient-driven innovation(s) as defined by } \\
\text { three criteria: }\end{array}$ & $\begin{array}{l}\text { Article is out of scope (context other than healthcare) } \\
\text { N.1. Based on WHO's definition of health innovations the }\end{array}$ \\
\hline
\end{tabular}

innovation identifies new or improved health policies, systems, products and technologies, or services and delivery methods that improve people's health and well-being. The innovation aims to add value in the form of improved efficiency, effectiveness, quality, sustainability, safety and/or affordability. The innovation can be preventive, promotive, curative, rehabilitative, assistive and/or palliative care.

4.2. The innovation is user driven, meaning that it is both initiated and driven (in development, implementation, etc) by patients and/or family caregivers.

4.3. The innovation responds to one or more unmet needs of the innovator. Unmet needs are defined by the innovator.

$\begin{array}{ll}\text { 5. The innovation is the focus of the article } & \begin{array}{l}\text { The innovation is used for data collection but not described in } \\ \text { the article }\end{array}\end{array}$


presented original data not presented elsewhere were included. We limited the review to reports and publications made from the year 2008 and onwards because our initial searches found few reports or publications about patient innovations before 2008. Articles where the innovation (primarily the online platform PatientsLikeMe) was used solely for data collection were excluded.

\section{Information sources}

Four electronic databases were searched in October 2019 and the search was updated in December 2020: Medline (Ovid), Web of Science Core Collection, PsycINFO (Ovid) and Cinahl (Ebsco). We also employed snowball sampling: (1) The webpage www.patient-innovation.com was screened for names of innovators and innovations and those names were used to search records in PubMed (January 2020); (2) Reference lists of included articles were screened (August 2020) and (3) Names of identified patient innovators were used for author search in Web of Knowledge (August 2020).

\section{Search}

Key articles on patient-driven innovations were used by MR to form a search strategy in consultation with librarians at the Karolinska Institutet University Library. The search strategy was tested and refined three times to ensure that all key articles were identified. A complete search strategy for Web of Science is presented in table 2 and for all databases (Medline (Ovid), Web of Science Core Collection, PsycINFO (Ovid) and Cinahl (Ebsco) in online supplemental appendix 2.

\section{Selection of sources of evidence}

Records were screened by six authors (MR, AB, HJ, $\mathrm{SR}, \mathrm{HH}$ and $\mathrm{CW}$ ) and two research assistants (see the Acknowledgements section) in the open-source software Rayyan, ${ }^{16}$ according to eligibility criteria. To screen the large number of records identified at this stage, we first collected and applied the selection criteria to titles and abstracts of the papers discovered in the search. When

\section{Table 2 Search strategy used in MEDLIN}

Interface: Ovid MEDLINE(R) and Epub Ahead of Print, In-Process \& Other Non-Indexed Citations and Daily Date of Search: 15 October 2019 Number of hits: 3443 Comment: In Ovid, two or more words are automatically searched as phrases; that is, no quotation marks are needed
Field labels .

- exp/=explodedMeSH term

- I=non exploded MeSH term

- ti,ab,kf.=title, abstract and author keywords

- adjx=within $x$ words, regardless of order

${ }^{*}=$ truncation of word for alternate endings

\begin{tabular}{|c|c|c|}
\hline \# & Searches & Results \\
\hline 1 & $\begin{array}{l}\text { ((adult child }{ }^{\star} \text { or patient }{ }^{\star} \text { or caregiver }{ }^{\star} \text { or caregiver }{ }^{\star} \text { or carer }^{\star} \text { or family or husband* } \\
\text { or "next of kin*" or partner }{ }^{\star} \text { or spouse* or user or wife or wives) adj1 (directed or } \\
\text { driven or driving or initiated)).ti,ab,kf. }\end{array}$ & 4150 \\
\hline 2 & $\begin{array}{l}\text { (co creat* or co design* or collaborative creation* or collaborativ* }{ }^{\star} \text { created or "do } \\
\text { it yourself" or "doing it for themselves" or diy or e patient* or lead patient* or } \\
\text { participatory design* or public driven or superuser").ti,ab,kf. }\end{array}$ & 3444 \\
\hline 4 & or/1-3 & 31910 \\
\hline 5 & Equipment design/ & 144620 \\
\hline 6 & Inventions/ & 1720 \\
\hline 7 & Organisational innovation/ & 23978 \\
\hline 8 & Diffusion of Innovation/ & 17239 \\
\hline 12 & exp Self care/ & 52825 \\
\hline 13 & $\begin{array}{l}\text { (assistive technolog* or co care or self care or self help device* or self } \\
\text { management* or self monitor* or self track*).ti,ab,kf. }\end{array}$ & 42096 \\
\hline 14 & or/5-13 & 388764 \\
\hline 15 & 4 and 14 & 3235 \\
\hline 16 & (co innovat* or patient* innovat* or patient design*).ti,ab,kf. & 219 \\
\hline 17 & 15 or 16 & 3443 \\
\hline
\end{tabular}


abstracts were not available, we retrieved the full paper to decide if the selection criteria were met or not met to carry forward to the next stage of the review.

Screening was blinded and a minimum of two researchers conducted the screening for each article. Inclusion/exclusion decisions were compared. In $7 \%$ of the cases, researchers disagreed about inclusion/exclusion, and these conflicts were resolved by consensus through discussion among authors based on a full-text screening.

\section{Data charting process and data items}

A template for data charting in Microsoft Excel 2013 was developed iteratively by all authors, who worked in pairs to extract data. Extractions were compared within the pairs by those who extracted the data and merged by MR.

The final extraction form included items on the characteristics of the studies (journal, publication year, first author country of affiliation, publication type, study aim, study design, data and sample size), and on the innovations (name of innovation, name of innovator(s), description of innovation, unmet needs that the innovations aimed to fulfil, and medical condition). Extracted data is published in online supplemental appendix 3.1-3.3.

\section{Analysis of review findings}

MR performed an initial overview of the extracted data and proposed preliminary categories for each data item. $\mathrm{PM}, \mathrm{CW}, \mathrm{CS}, \mathrm{HH}, \mathrm{AB}$ and $\mathrm{HJ}$ worked in pairs with sorting the data according to suggested categories and refined the categories and suggested additional categories when needed. Detailed description of the categorisation of data ispresented in online supplemental appendix 4.

\section{Patient and public involvement}

This study was performed within the auspices of the cocreated research programme 'Patients in the driver's seat! A multimethod partnership programme on patient-driven innovations', where patient innovators are engaged as equal partners in research. The research programme members were engaged in the research meetings and contributed to the research questions, definition of patient-driven innovations and selection of sources of evidence (see the Acknowledgements section). Furthermore, SR, a patient researcher ${ }^{17}$ living with Parkinson's disease, coauthored the current paper and was involved in all stages of the process.

\section{FINDINGS}

The systematic search generated 7220 records after duplicates were removed; the snowball sampling generated 559 additional records. In total, 7629 records were screened by title and abstract and 414 records were screened in full text for eligibility. Of these, 96 articles on 20 patientdriven innovations were included. The study selection process is reported in a PRISMA flow diagram (figure 1).

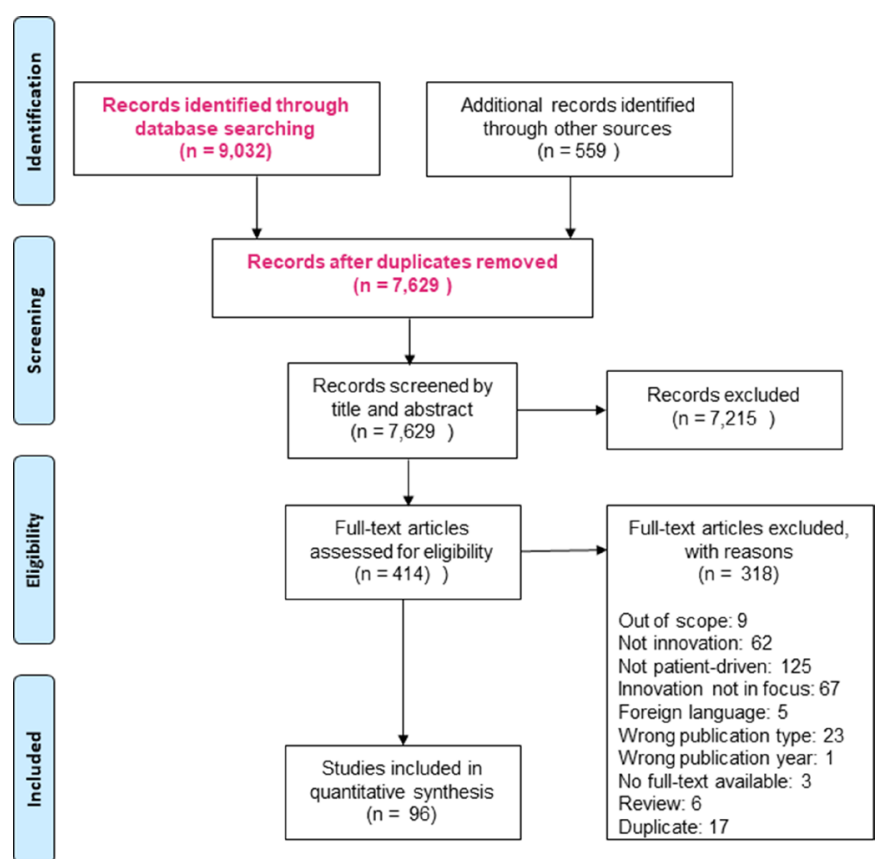

Figure 1 PRISMA 2009 flow diagram. PRISMA, Preferred Reporting Items for Systematic Reviews and Meta-Analyses.

\section{The nature of patient-driven innovations}

The 20 identified innovations addressed the unmet needs of patients and family caregivers with diabetes (7 innovations, 46 publications ${ }^{18-63}$ ); cancer (1 innovation, 1 publication ${ }^{64}$ ); rare diseases ( 3 innovations, 5 publications ${ }^{65-69}$ ); gastrointestinal diseases (2 innovations, 4 publications ${ }^{70-73}$ ); disabilities (2 innovations, 3 publications ${ }^{74-76}$ ); Parkinson's disease (2 innovations, 3 publications ${ }^{77-79}$ ) and mental illness (1 innovation, 2 publications $\left.{ }^{80}\right)$. There were also innovations targeting unmet needs of multiple conditions (2 innovations, 32 publications $\left.{ }^{82-113}\right)$. Data by innovation are presented in table 3.

Many of the innovations involved digital technologies, with four mobile apps, four collaborative networks, five technical innovations for diabetes care and one sensor that measures output volume from one's ostomy. Other innovations included one jacket with pockets for postoperative drain tubes, one pen-and-paper form for personalised medical records, a painted staircase (optical illusion) to prevent gait freezing, and ingestion of pig-worms to improve symptoms from Crohn's disease. Among the 20 innovations reported, the Do-It-Yourself Artificial Pancreas System (DIYAPS) and PatientsLikeMe. com, an online health-related social network, accounted for half of the articles.

\section{Extent of publications}

Author affiliations were exclusively in high income countries with $56 \%$ of first authors with affiliations in North America, followed by $36 \%$ from European countries (see table 4). One first author had their affiliation in Asia and six in Oceania. The number of publications increased in later years, with $69 \%$ of articles published 2016-2020 
Table 3 Innovation-specific information

\begin{tabular}{|c|c|c|c|c|c|}
\hline Medical condition & Innovation & $\mathbf{N}$ articles & $\begin{array}{l}\text { Innovator(s) mentioned in the } \\
\text { article(s) }\end{array}$ & $\begin{array}{l}\text { Type of } \\
\text { innovation }\end{array}$ & $\begin{array}{l}\text { Innovator(s) } \\
\text { listed as author }\end{array}$ \\
\hline $\begin{array}{l}\text { Cancer (breast } \\
\text { cancer) }\end{array}$ & Jacki Jacket & 1 & Cathy McGrath & Patient clothing & No \\
\hline \multirow[t]{5}{*}{ Diabetes } & Autosens & 1 & Dana Lewis, Scott Leibrand & $\begin{array}{l}\text { Technical } \\
\text { innovation for } \\
\text { diabetes care }\end{array}$ & Yes \\
\hline & $\begin{array}{l}\text { DIYAPS, Do-It- } \\
\text { Yourself Artificial } \\
\text { Pancreas System }\end{array}$ & 21 & $\begin{array}{l}\text { \#wearenotwaiting-community, } \\
\text { Dana Lewis, Adrien Tappe, } \\
\text { Bastian Hauck, Tebbe Ubbe, } \\
\text { Saskia Wolf, Timothy Omer }\end{array}$ & $\begin{array}{l}\text { Technical } \\
\text { innovation for } \\
\text { diabetes care }\end{array}$ & Yes \\
\hline & Omnipod & 2 & John Brooks III & $\begin{array}{l}\text { Technical } \\
\text { innovation for } \\
\text { diabetes care }\end{array}$ & Yes \\
\hline & T1resources.uk & 1 & Mike Kendall & Online network & Yes \\
\hline & Webdia & 1 & Jean-Luc Mando & Mobile app & Yes \\
\hline \multirow[t]{2}{*}{ Disabilities } & Upsee & 2 & Debby Elnatan & Wearable devise & No \\
\hline & $\begin{array}{l}\text { (No name) } \\
\text { Auditory } \\
\text { stimulation }\end{array}$ & 1 & Debby Elnatan & $\begin{array}{l}\text { Auditory } \\
\text { stimulation }\end{array}$ & Yes, last author \\
\hline \multirow[t]{2}{*}{ Multiple } & PatientsLikeMe & 29 & $\begin{array}{l}\text { Jamie Heywood, Benjamin } \\
\text { Heywood, Jeff Cole }\end{array}$ & Online network & Yes in some \\
\hline & Medistory & 1 & Olive O'Connor & $\begin{array}{l}\text { pen and paper } \\
\text { medical journal }\end{array}$ & Yes \\
\hline \multirow[t]{2}{*}{ Parkinson's disease } & $\begin{array}{l}\text { No name (A } \\
\text { painted staircase) }\end{array}$ & 2 & Mileha Soneji & $\begin{array}{l}\text { Paint on floor, } \\
\text { optical illusion }\end{array}$ & Yes \\
\hline & $\begin{array}{l}\text { No name (a } \\
\text { smartphone app } \\
\text { for collecting data } \\
\text { on drug intake and } \\
\text { well-being) }\end{array}$ & 1 & Sara Riggare & Mobile app & Yes \\
\hline $\begin{array}{l}\text { Rare diseases } \\
\text { (22q11 deletion } \\
\text { syndrome) }\end{array}$ & $\begin{array}{l}\text { (No name) patient } \\
\text { driven collaborative } \\
\text { initiative }\end{array}$ & 1 & Anne Lawlor & $\begin{array}{l}\text { Collaborative } \\
\text { network }\end{array}$ & Yes \\
\hline \multirow[t]{2}{*}{$\begin{array}{l}\text { Rare diseases (cystic } \\
\text { fibrosis (CF)) }\end{array}$} & $\begin{array}{l}\text { Upstream dream, } \\
\text { Genia }\end{array}$ & 2 & Andreas Hager & Mobile app & Yes \\
\hline & $\begin{array}{l}\text { Sweden CF } \\
\text { Coalition }\end{array}$ & 2 & Andreas Hager & $\begin{array}{l}\text { Collaborative } \\
\text { network }\end{array}$ & Yes \\
\hline
\end{tabular}

DIYAPS, Do-It-Yourself Artificial Pancreas System. 


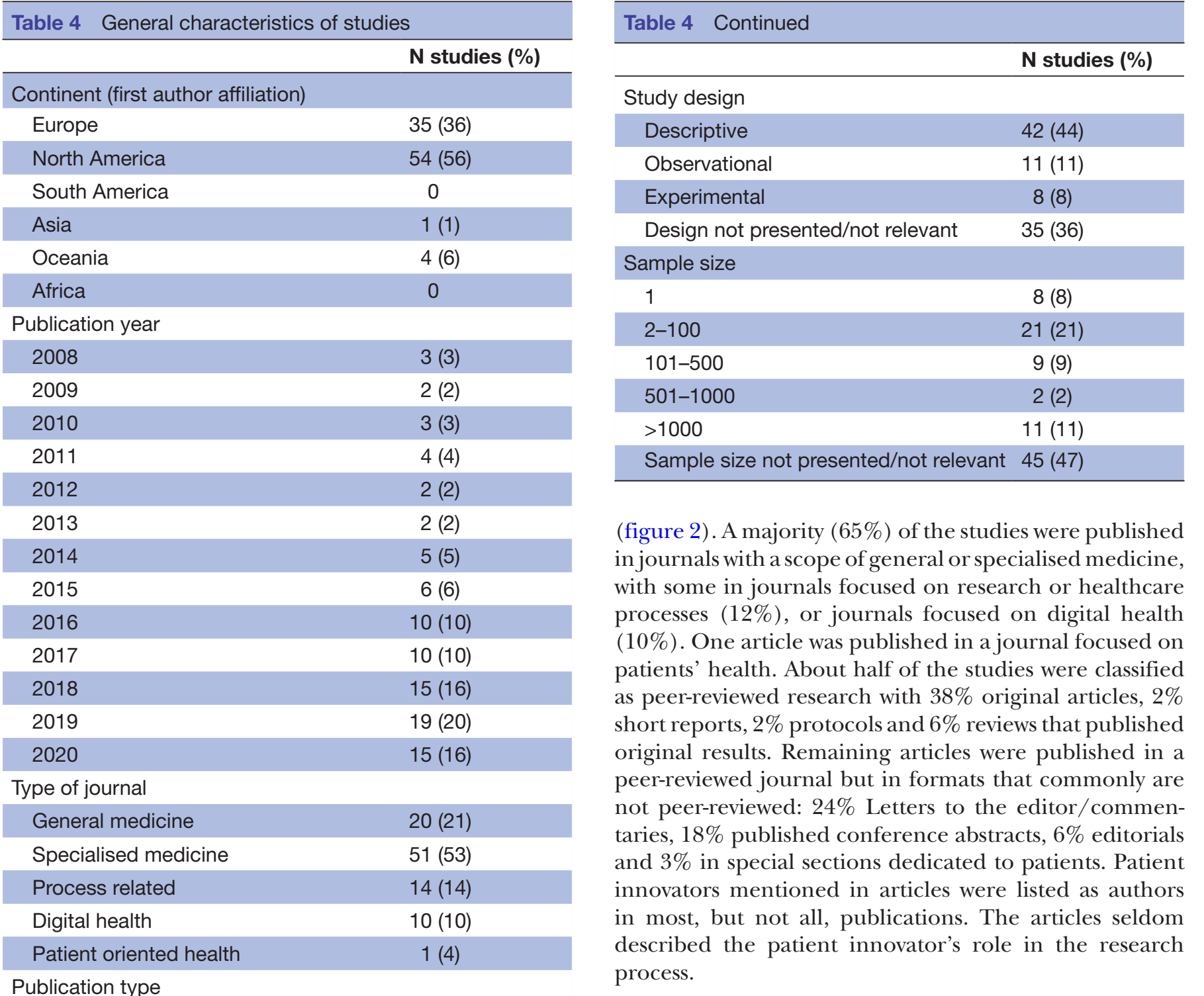

\begin{tabular}{lc} 
Original research & $34(35)$ \\
\hline Short report & $2(2)$ \\
Protocol & $2(2)$ \\
Review (presenting original results) & $6(6)$ \\
Letter to editor/commentary & $25(26)$ \\
Conference abstract & $17(18)$ \\
Editorial & $7(7)$ \\
$\begin{array}{l}\text { Special section dedicated to patients } \\
\text { Study aim }\end{array}$ & $3(3)$ \\
$\begin{array}{l}\text { Describe the innovation and/or } \\
\text { development of innovation }\end{array}$ & $23(24)$ \\
$\begin{array}{l}\text { Describe users and/or how users } \\
\text { perceive the innovation }\end{array}$ & $21(22)$ \\
$\begin{array}{l}\text { Test effect/impact of innovations } \\
\text { Describe/discuss ethical issues and/or } \\
\text { policy change }\end{array}$ & $83(8)$ \\
Test feasibility of innovation & $2(2)$ \\
\hline Aim not presented/not relevant & $19(18)$ \\
\hline
\end{tabular}

\section{Aims and design of included articles}

Almost half of the studies (47\%) used a descriptive design, while smaller proportions used an observational design $(15 \%)$ or experimental design $(9 \%)$ and $29 \%$ of the articles were categorised as not having a study design, for

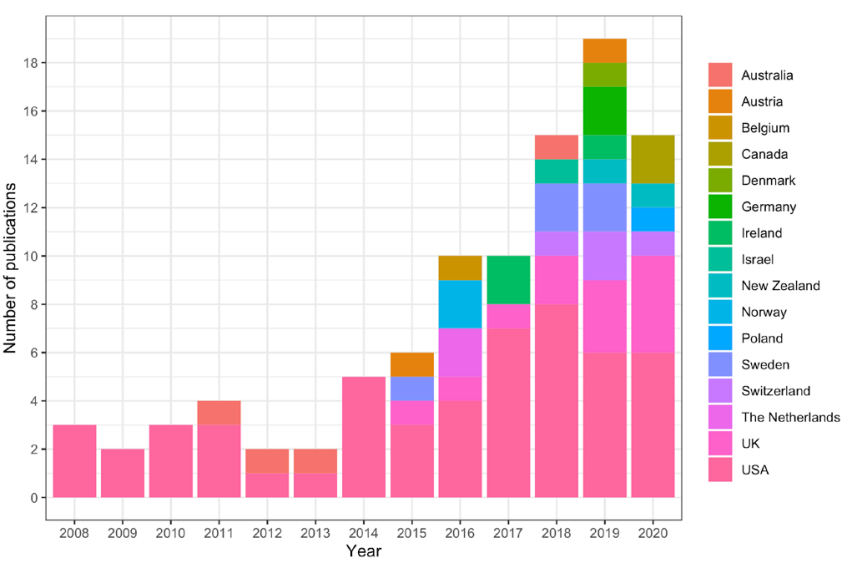

Figure 2 Number of publications per year. 
example, editorials. Sample sizes ranged from one participant (8\% of studies) to over 1000 participants (14\% of studies). Of the 96 articles included, $77 \%$ presented a study aim, and approximately one-third of these had a study aim that focused on describing or testing the innovation: $24 \%$ aimed to describe the innovation and/or the development of the innovation, $24 \%$ to test the effect and/or impact of the innovation and $2 \%$ to test the feasibility of the innovation. Other articles aimed to describe characteristics of users of the innovation and/or describe how users perceived the innovation (22\%). A small proportion of the articles described and discussed ethical issues and/or or policy changes relating to patient-driven innovations $(8 \%)$.

\section{DISCUSSION}

This article reports a scoping review of publications about patient-driven innovations in peer-reviewed journals. The review identified 96 articles published from year 2008 to 2020, reporting 20 different patient-driven innovations and the number of publications increased in the later years. Among the 20 innovations reported, 'DIYAPS' and the online health network 'PatientsLikeMe' accounted for half of the articles. Considering that over 1200 patient-driven innovations are listed on www.patient-innovation.com, the number of 20 patient-driven innovations published in peer-reviewed journals is remarkably small.

Canhao et at point out that the lack of patients scaling up and spreading their innovations to others may be an example of market failure. Based on the potential benefits of patient-driven innovations, actors such as medical product and service producers and government regulators could support patient innovators in the development and diffusion of their innovations. ${ }^{114}$ We suggest that the lack of patient-driven innovations reported in peerreviewed journals may also be seen as an academic failure as scientific peer-reviewed journals are important arenas for disseminating, evaluating, improving and discussing ideas in healthcare. The research community has an important part to play in complementing other ways of support for the creative contributions of the patients by using the systematic methods of research to evaluate, develop, and integrate these solutions into patients' daily lives and healthcare systems. According to Canhao et $a l,{ }^{9}$ there are several barriers for patient innovators that prevent them from sharing their innovations, including lack of resources, skills or access to the process of approval and commercialisation. In this review, only a minor portion of the studies had an observational or experimental design, and it is possible that similar barriers that prevent patient innovators from sharing their innovations apply to research and scientific writing.

\section{Strengths and limitations}

The strengths of the study include the broad scope of the review. We followed the process outlined in Arksey and $\mathrm{O}^{\prime}$ Malley ${ }^{13}$ and the review was guided by a predetermined strategy for data collection and analysis. Methodological strengths lie in this systematic approach to searching the four large databases, complemented by snowball sampling. Earlier research has reviewed specific patientdriven innovations, for example, a review of 'DIYAPS' by Kesavadev $e t a l,{ }^{115}$ or investigated characteristics of patient innovators. ${ }^{7}$ This is the first review undertaken of patientdriven innovations, according to a broad and comprehensive definition, and one of the very few undertaken of innovations in which patients have played a significant role in development of the innovation. This builds on Oliveira et als definition of patient innovations where innovation is limited to 'a treatment, a technical aid product, or a medical device'. ${ }^{7}$ We cocreated a broader definition together with patient innovators in order to include social innovations such as collaborative or social networks. Thus, this broader scope and definition of patient-driven innovations was able to capture more innovations in which patients have played a significant role in the development.

The limitations of the study include the choice to only select peer-reviewed articles, but this was motivated by our aim to explore the proliferation of patient-driven innovations within the scientific literature. If the purpose had been to create an inventory of patient-driven innovations, the inclusion of grey literature would have yielded more results. Furthermore, the source of information was restricted to the included articles and in some cases the webpage wwwpatient-innovationcom. Patient-driven innovations are not always labelled as such in the publications. Therefore, despite the broader definition and the use of snowball sampling and online searches to identify the drivers of innovations, our results are likely an under-representation of research on patient-driven innovations. Also, as patient-driven innovations may initially go through commercialisation processes with a shift of 'drivers', it is possible that we would relabel some innovations as not being patient driven if we had access to more information.

\section{Unanswered questions and future research}

As this field of research is relatively new, there are several unanswered questions for future research. Considering the potential benefits that patient-driven innovations can have if they become widely used, it will be important to understand factors that may facilitate or hinder implementation, spread and scale-up of patient-driven innovations; none of the included articles in this review systematically examined these questions. It may also be important to gain deeper understanding of patient-driven innovations in general, what unmet user need they address, how they are used and by whom and what outcomes they have for patients and healthcare systems. A further unanswered question is what determines whether patient innovators decide to publish their results and if so, in which journal(s). Patient innovators were often listed as coauthors in publications related to their innovations, there was a broad variation in type of publication, and it was common 
for patient innovators to coauthor articles together with established researchers and/or clinicians. Some patient innovators presented their innovations in single authored papers and others were not listed as authors. A suggestion for future studies is to interview or survey patient innovators who publish in peer-reviewed journals and explore how their reasoning around research collaboration and publishing.

This review was restricted to innovations, and we acknowledge that we, in the study selection, have excluded studies published by patient researchers if the studies were not related to patient-driven innovations. For further research we suggest a review of literature published by patient researchers and citizen scientists in general.

\section{CONCLUSIONS}

Peer-reviewed publications on patient-driven innovations are increasing and peer-reviewed journals constitute an arena where patient-driven innovations can be evaluated, discussed and developed further. We see an important opportunity for researchers and clinicians to support patient innovators' research and publication while being mindful about not taking over the work of the innovators themselves.

Twitter Sara Riggare @SaraRiggare, John Øvretveit @jovret, Carl Savage @ SavageCarl, Carolina Wannheden @linawannheden and Henna Hasson @ProcomeKI

Acknowledgements The authors would like to thank all the members in the 'Patients in the driver's seat! A multimethod partnership programprogramme on patient-driven innovations' research team who collaborated on the definition of patient-driven innovations used in the present article, particularly Åsa Steinsaphir and Andreas Hager, who reviewed the definition of patient-driven innovations. The systematic database search in this review was performed by Magdalena Svanberg \& Emma-Lotta Säätelä at the Karolinska Institutet University Library. Furthermore, the authors thank research assistants Lana Al Soufi, Sofia Larsson and Clara Lindberg for screening of articles and Elizabeth Blum who extracted data and reviewed the manuscript for English language. Preliminary findings of this scoping review were previously presented at the European Health Management Association (EHMA) conference 2020.

Contributors MR, AB, Jø, SR, CS, CW and $\mathrm{HH}$ conceived and planned the review and defined central concepts; MR designed the search strategy in collaboration with Magdalena Svanberg \& Emma-Lotta Säätelä at the Karolinska Institutet University Library. MR, AB, HJ, SR, HH and CW identified relevant studies; MR, AB,

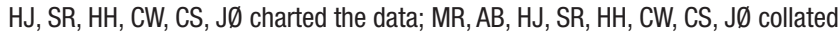
and summarized results; MR, PM and HH drafted the first version of the paper. CW generated figure 1. HH was responsible for the overall content as the guarantor. All authors revised orrevised or critically reviewed the paper and read and approved the final draft.

Funding This work was supported by the Swedish Research Council for Health, Working Life and Welfare (FORTE) grant number 2018-01472.

Competing interests None declared.

Patient consent for publication Not applicable.

Ethics approval This study does not involve human participants.

Provenance and peer review Not commissioned; externally peer reviewed.

Data availability statement All data relevant to the study are included in the article or uploaded as online supplemental information. Online Supplemental files with the complete search strategy, extracted data by article and an explanation of how extracted data was categorised is available in online supplemental appendices $1-4$.
Supplemental material This content has been supplied by the author(s). It has not been vetted by BMJ Publishing Group Limited (BMJ) and may not have been peer-reviewed. Any opinions or recommendations discussed are solely those of the author(s) and are not endorsed by BMJ. BMJ disclaims all liability and responsibility arising from any reliance placed on the content. Where the content includes any translated material, BMJ does not warrant the accuracy and reliability of the translations (including but not limited to local regulations, clinical guidelines, terminology, drug names and drug dosages), and is not responsible for any error and/or omissions arising from translation and adaptation or otherwise.

Open access This is an open access article distributed in accordance with the Creative Commons Attribution Non Commercial (CC BY-NC 4.0) license, which permits others to distribute, remix, adapt, build upon this work non-commercially, and license their derivative works on different terms, provided the original work is properly cited, appropriate credit is given, any changes made indicated, and the use is non-commercial. See: http://creativecommons.org/licenses/by-nc/4.0/.

\section{ORCID iDs}

Maria Reinius http://orcid.org/0000-0003-0864-8701

Pamela Mazzocato http://orcid.org/0000-0001-9283-6451

Sara Riggare http://orcid.org/0000-0002-2256-7310

Ami Bylund http://orcid.org/0000-0001-7118-4933

Hanna Jansson http://orcid.org/0000-0002-1615-0463

John Øvretveit http://orcid.org/0000-0002-5177-6613

Carl Savage http://orcid.org/0000-0003-2836-903X

Carolina Wannheden http://orcid.org/0000-0003-2122-1083

Henna Hasson http://orcid.org/0000-0002-3827-6841

\section{REFERENCES}

1 Oliveira P, Zejnilović L, Canhão H. Challenges and Opportunities in Developing and Sharing Solutions by Patients and Caregivers: The Story of a Knowledge Commons for the Patient Innovation Project. In: Frischmann BM, Strandburg KJ, Madison MJ, eds. Cambridge studies on governing knowledge commons. Cambridge: Governing Medical Knowledge CommonsCambridge University Press, 2017: 301-25.

2 Lindblad S, Ernestam S, Van Citters AD, et al. Creating a culture of health: evolving healthcare systems and patient engagement. QJM 2017;110:125-9.

3 Alakeson V. Let patients control the purse strings. BMJ 2008;336:807-9.

4 Dent M, Pahor M. Patient involvement in Europe--a comparative framework. J Health Organ Manag 2015;29:546-55.

5 Riggare S. E-patients hold key to the future of healthcare. BMJ 2018;360:k846.

6 Snow R, Humphrey C, Sandall J. What happens when patients know more than their doctors? experiences of health interactions after diabetes patient education: a qualitative patient-led study. BMJ Open 2013;3:e003583.

7 Oliveira P, Zejnilovic L, Canhão $\mathrm{H}$, et al. Innovation by patients with rare diseases and chronic needs. Orphanet J Rare Dis 2015;10:41.

8 deBronkart D. From patient centred to people powered: autonomy on the rise. BMJ 2015;350:h148.

9 Canhao H, Zejnilovic L, Oliveira P. Revolutionising healthcare by empowering patients to innovate. EMJ Innov 2017;1:31-4.

10 Oliveira P, Azevedo S, Canhão H. Empowering patients to innovate: the case of Patient Innovation. In: lakovleva T, Oftedal E, Bessant $\mathrm{J}$, eds. Responsible innovation in digital health. Edward Elgar Publishing, 2019: 42-5.

11 Kanstrup AM, Christiansen E. User-driven innovation as mutual but asymmetrical learning. International Journal of Technology and Human Interaction 2009;5:1-12.

12 Oliveira P, Zejnilovic L, Azevedo S, et al. Peer adoption and development of health innovations by patients: national representative study of 6204 citizens. J Med Internet Res 2019;21:e11726.

13 Arksey H, O'Malley L. Scoping studies: towards a methodological framework. Int J Soc Res Methodol 2005;8:19-32.

14 Tricco AC, Lillie E, Zarin W, et al. PRISMA extension for scoping reviews (PRISMA-ScR): checklist and explanation. Ann Intern Med 2018; $169: 467-73$.

15 Walker LO, Avant KC. Strategies for theory construction in nursing. 5. ed. Upper Saddle River, N.J: Prentice Hall, 2011.

16 Ouzzani M, Hammady H, Fedorowicz Z, et al. Rayyan-a web and mobile APP for systematic reviews. Syst Rev 2016;5:210. 
17 Riggare S. Patient researchers - the missing link? Nat Med 2020;26:1507.

18 Barnard KD, Ziegler R, Klonoff DC, et al. Open source closed-loop insulin delivery systems: a clash of cultures or merging of diverse approaches? J Diabetes Sci Technol 2018;12:1223-6.

19 Beckman D, Reehorst CM, Henriksen A, et al. Better glucose regulation through enabling group-based motivational mechanisms in cloud-based solutions like Nightscout. Int J Integr Care 2016;16:4

20 Braune K, O'Donnell S, Cleal B, et al. Real-World use of do-ityourself artificial pancreas systems in children and adolescents with type 1 diabetes: online survey and analysis of self-reported clinical outcomes. JMIR Mhealth Uhealth 2019;7:e14087.

21 Braune K, O'DONNELL S, Cleal B, et al. 117-LB: DIWHY: factors influencing motivation, barriers, and duration of DIY artificial pancreas system use among real-world users. Diabetes 2019;68:3.

22 Burnside $\mathrm{M}$, Crocket $\mathrm{H}$, Mayo M, et al. Do-It-Yourself automated insulin delivery: a leading example of the Democratization of medicine. J Diabetes Sci Technol 2020;14:878-82.

23 Cleal B, Braune K, O'DONNELL S, et al. 78-LB: detailing the experiences of people with diabetes using do-it-yourself artificial pancreas Systems-Qualitative analysis of responses to openended items in an international survey. Diabetes 2019;68:2.

24 Crabtree TSJ, McLay A, Wilmot EG. DIY artificial pancreas systems: here to stay? Practical Diabetes 2019;36:63-8.

25 de Bock $M$. The 'do it yourself' type 1 diabetes dilemma for medical practitioners. Intern Med J 2019;49:559-61.

26 Debong F, Mayer H, Kober J. Real-World assessments of mySugr mobile health APP. Diabetes Technol Ther 2019;21:S35-40.

27 Dowling L, Wilmot EG, Choudhary P. Do-It-Yourself closedloop systems for people living with type 1 diabetes. Diabet Med 2020;37:1977-80

28 Farrington C. Hacking diabetes: DIY artificial pancreas systems. Lancet Diabetes Endocrinol 2017;5:332.

29 Hng T-M, Burren D. Appearance of do-it-yourself closed-loop systems to manage type 1 diabetes. Intern Med J 2018;48:1400-4.

30 Hussain S, Lewis D. Diabetes podcast: do it Yourself/Open source artificial pancreas systems: Part 2. Diabetes Ther 2020;11:1621-6.

31 Hussain S, Lewis D. Diabetes Podcast: Do It Yourself/Open Source Artificial Pancreas Systems: Part 1. Diabetes Ther 2020;11:1609-19.

32 Jennings P, Hussain S. Do-It-Yourself artificial pancreas systems: a review of the emerging evidence and insights for healthcare professionals. J Diabetes Sci Technol 2020;14:868-77.

33 Kendall M, Cleverly L, Winchcombe K, et al. T1resources.uk; rated, reviewed, reliable. A co-created website for people affected by type 1 diabetes. British Journal of Diabetes 2017:17:111-4

34 Klee P, Bussien C, Castellsague M, et al. An intervention by a Patient-Designed do-it-yourself mobile device APP reduces $\mathrm{HbA} 1 \mathrm{c}$ in children and adolescents with type 1 diabetes: a randomized double-crossover study. Diabetes Technol Ther 2018;20:797-805.

35 Kublin O, Stępień M. Effect of using the NIGHTSCOUT system on metabolic control, safety, and incidence of complications in patients with diabetes mellitus. Wiad Lek 2020;73:1427-33.

36 Lebenthal Y, Lazar L, Benzaquen $\mathrm{H}$, et al. Patient perceptions of using the OmniPod system compared with conventional insulin pumps in young adults with type 1 diabetes. Diabetes Technol Ther 2012;14:411-7.

37 Lee JM, Hirschfeld E, Wedding J. A Patient-Designed do-it-yourself mobile technology system for diabetes: promise and challenges for a new era in medicine. JAMA 2016;315:1447-8.

38 Lee JM, Newman MW, Gebremariam A, et al. Real-World use and self-reported health outcomes of a Patient-Designed do-it-yourself mobile technology system for diabetes: lessons for mobile health. Diabetes Technol Ther 2017;19:209-19.

39 Lemieux P, Yamamoto J, Donovan L. 44 - Do-It-Yourself Artificial Pancreas System Use in Pregnancy in a Real-World Setting: A Case Report. Virtual Diabetes Canada/CSEM Professional Conference, October 28-30, 2020. Canadian Journal of Diabetes 2020;44:S20-S.

40 Lewis D. Setting expectations for successful artificial Pancreas/ Hybrid closed Loop/Automated insulin delivery adoption. J Diabetes Sci Technol 2018;12:533-4.

41 Lewis D. History and perspective on DIY closed looping. J Diabetes Sci Technol 2019:13:790-3.

42 Lewis D, Leibrand S, Open APS, \#OpenAPS Community. RealWorld use of open source artificial pancreas systems. J Diabetes Sci Technol 2016;10:1411.

43 Lewis DM, Grant AD. 1056-P: characterization of Multi-timescale biological rhythms in individuals with type 1 diabetes. Diabetes 2019;68:2.
44 Lewis DM, Leibrand S. How a DIY artificial pancreas built by a patient makes new tools available for clinicians. Diabetes 2020;64:A638-A

45 Lewis DM, Leibrand S. Automatic estimation of Basals, ISF, and CARB ratio for sensor-augmented pump and hybrid closed-loop therapy. Diabetes 2017;66:LB33-LB.

46 Lewis DM, Leibrand S, Street TIMJ, et al. Detecting insulin sensitivity changes for individuals with type 1 diabetes. Diabetes 2018;67:2

47 Lewis DM, Swain RS, Donner TW. Improvements in A1c and Timein-Range in DIY closed-loop (OpenAPS) users. Diabetes 2018;67:2.

48 Litchman ML, Lewis D, Kelly LA, et al. Twitter Analysis of \#OpenAPS DIY Artificial Pancreas Technology Use Suggests Improved A1C and Quality of Life. J Diabetes Sci Technol 2019;13:164-70.

49 Litchman ML, Walker HR, Fitzgerald C, et al. Patient-Driven Diabetes Technologies: Sentiment and Personas of the \#WeAreNotWaiting and \#OpenAPS Movements. J Diabetes Sci Technol 2020;14:990-9.

50 Mader JK, Sourij H, Laimer M. Influence of frequent use of mobile health technology on blood glucose control in patients with type 1 diabetes. Diabetes technology \& therapeutics 2019;17:A124-5.

51 Marshall DC, Holloway M, Korer M, et al. Do-It-Yourself artificial pancreas systems in type 1 diabetes: perspectives of two adult users, a caregiver and three physicians. Diabetes Ther 2019;10:1553-64.

52 Melmer A, Züger T, Lewis DM, et al. Glycaemic control in individuals with type 1 diabetes using an open source artificial pancreas system (OpenAPS). Diabetes Obes Metab 2019;21:2333-7.

53 Melmer A, Zuger T, Lewis DM, et al. 76-OR: in-depth review of glycemic control and glycemic variability in people with type 1 diabetes using open source artificial pancreas systems. Diabetes 2019;68:2

54 Murray JA, Clayton MF, Litchman ML. Health care provider knowledge and perceptions of FDA-approved and do-ityourself automated insulin delivery. J Diabetes Sci Technol 2020;14:1017-21.

$55 \mathrm{Ng} \mathrm{M}$, Borst E, Garrity A, et al. Evolution of do-it-yourself remote monitoring technology for type 1 diabetes. J Diabetes Sci Technol 2020;14:854-9.

56 O'Donnell S, Lewis D, Marchante Fernández M, et al. Evidence on User-Led innovation in diabetes technology (the open project): protocol for a mixed methods study. JMIR Res Protoc 2019;8:e15368.

57 Oliver N, Reddy M, Marriott C, et al. Open source automated insulin delivery: addressing the challenge. NPJ Digit Med 2019;2:124.

58 Schroeder EB, Desai J, Schmittdiel JA, et al. An innovative approach to informing research: gathering perspectives on diabetes care challenges from an online patient community. Interact $J$ Med Res 2015;4:35-48.

59 Shaw D, Crabtree TSJ, Hammond P, et al. The DIY artificial pancreas system: an ethical dilemma for doctors. Diabet $\mathrm{Med}$ 2020;37:1951-3.

60 Shepard JA, Breton M, Nimri R, et al. User and healthcare professional perspectives on do-it-yourself artificial pancreas systems: a need for guidelines. J Diabetes Sci Technol 2022;16:224-227.

61 Zabinsky J, Howell H, Ghezavati A, et al. 988-P: do-ityourself artificial pancreas systems for type 1 diabetes reduce hyperglycemia without increasing hypoglycemia. Diabetes 2020;69.

62 Zisser H, Breton M, Dassau E, et al. Novel methodology to determine the accuracy of the OmniPod insulin pump: a key component of the artificial pancreas system. J Diabetes Sci Technol 2011;5:1509-18.

63 Årsand E, Bradway M, Muzny M, et al. Warning: the do-it-yourself (DIY) wave will drastically change diabetes care! Int $J$ Integr Care 2016;16:2.

64 Berry DL, Blonquist TM, Halpenny B, et al. The Jacki jacket after mastectomy with reconstruction: a randomized pilot study. Breast Cancer Res Treat 2020:179:377-85.

65 Monestrol de I, Ericson P, Hjelte L. Co-creating the Swedish example for orderly introduction and follow-up of new therapies. Pediatr Pulmonol 2018;53:379.

66 Grande SW, Longacre MR, Palmblad K, et al. Empowering young people living with juvenile idiopathic arthritis to better communicate with families and care teams: content analysis of semistructured interviews. JMIR Mhealth Uhealth 2019;7:12.

67 Lawlor A, Kerin L, Orr D, et al. Developing integrated care in the context of rare chromosomal conditions: 22q11 deletion syndrome; a parent/clinician collaboration. Int J Integr Care 2017;17:215-2. 
68 Lindblad A, Hedborg A, Elidottir H. Sweden's learning health system approach to new therapies: nine months with lumacraftor/ivacraftor. Pediatr Pulmonol 2019;54:S444-S.

69 Longacre M, Grande S, Hager A, et al. Clinical adoption of mHealth technology to support pediatric cystic fibrosis care in Sweden: qualitative case study. JMIR Pediatr Parent 2018;1:e11080.

70 Ahrens S, Opening AS. Opening (and swallowing) a can of worms to treat my Crohn's disease. Am J Gastroenterol 2016;111:918-20.

71 Kontovounisios C, Smith J, Dawson P, et al. The Ostom-iTM alert sensor: a new device to measure stoma output. Tech Coloproctol 2018;22:697-701.

72 Rouholiman D, Gamble JG, Dobrota SD, et al. Improving healthrelated quality of life of patients with an ostomy using a novel digital wearable device: protocol for a pilot study. JMIR Res Protoc 2018;7:e82.

73 Seres M. From patient to Patient-Entrepreneur: development of an ostomy bag sensor. Am J Gastroenterol 2018;113:8-10.

74 Ardolino E, Flores M, Manella K. Gross motor outcomes after dynamic weight-bearing in 2 children with trunk hypotonia: a case series. Pediatr Phys Ther 2017;29:360-4.

75 Ben-Pazi H, Aran A, Pandyan A, et al. Auditory stimulation improves motor function and caretaker burden in children with cerebral palsya randomized double blind study. PLoS One 2018;13:12.

76 Fergus A. A novel mobility device to improve walking for a child with cerebral palsy. Pediatr Phys Ther 2017;29:E1-7.

77 Janssen S, Soneji M, Nonnekes J, et al. A painted staircase illusion to alleviate freezing of gait in Parkinson's disease. J Neurol 2016;263:1661-2.

78 Janssen S, van Wezel R, Soneji M, et al. Response to: staircase climbing is not solely a visual compensation strategy to alleviate freezing of gait in Parkinson's disease. J Neurol 2017;264:177-8.

79 Riggare S, Unruh KT. Patients organise and train doctors to provide better care. BMJ 2015;351:h6318.

80 Torous J, Roux S. Patient-driven innovation for mobile mental health technology: case report of symptom tracking in schizophrenia. JMIR Ment Health 2017;4:e27.

81 Vaidyam A, Roux S, Torous J. Patient innovation in investigating the effects of environmental pollution in schizophrenia: case report of digital phenotyping beyond Apps. JMIR Ment Health 2020;7:e19778.

82 Brownstein CA, Brownstein JS, Williams DS, et al. The power of social networking in medicine. Nat Biotechnol 2009;27:888-90.

83 Brownstein CA, Wicks P. The potential research impact of patient reported outcomes on osteogenesis imperfecta. Clin Orthop Relat Res 2010;468:2581-5.

84 Chiauzzi E, Wicks P. Digital trespass: ethical and Terms-of-Use violations by researchers accessing data from an online patient community. J Med Internet Res 2019;21:e11985

85 de la Loge C, Dimova S, Mueller K, et al. PatientsLikeMe® online epilepsy community: patient characteristics and predictors of poor health-related quality of life. Epilepsy Behav 2016;63:20-8.

86 Ellis L, Showell C, Turner P. Social media and patient selfmanagement: not all sites are created equal. Stud Health Technol Inform 2013;183:291-5.

87 Frost J, Massagli M. PatientsLikeMe the case for a data-centered patient community and how ALS patients use the community to inform treatment decisions and manage pulmonary health. Chron Respir Dis 2009;6:225-9.

88 Frost JH, Massagli MP. Social uses of personal health information within PatientsLikeMe, an online patient community: what can happen when patients have access to one another's data. J Med Internet Res 2008;10:e15.

89 Frost JH, Massagli MP, Wicks P, et al. How the social web supports patient experimentation with a new therapy: the demand for patient-controlled and patient-centered informatics. AMIA Annual Symposium proceedings AMIA Symposium, 2008:21721-21.
90 Griffiths F, Dobermann T, Cave JAK, et al. The impact of online social networks on health and health systems: a scoping review and case studies. Policy Internet 2015;7:473-96.

91 Heywood J, Zeliadt N. Straight talk with Jamie Heywood. Nat Med 2014;20:457.

$92 \mathrm{Li} \mathrm{J}$. Privacy policies for health social networking sites. J Am Med Inform Assoc 2013;20:704-7.

93 Ma X, Sayama H. Mental disorder recovery correlated with centralities and interactions on an online social network. PeerJ 2015;3:e1163.

94 O'Brien EC, Rodriguez AM, Kum H-C, et al. Patient perspectives on the linkage of health data for research: insights from an online patient community questionnaire. Int J Med Inform 2019;127:9-17.

95 O'Connor O. The MediStori. A personal health record and standardised self-management toolkit which can improve integrated care systems. Int J Integr Care 2017;17:475-5.

96 Okun S, Goodwin K. Building a learning health community: by the people, for the people. Learn Health Syst 2017;1:e10028.

97 Okun S, Wicks P. DigitalMe: a journey towards personalized health and thriving. Biomed Eng Online 2018;17:119.

98 Omer T. Empowered citizen 'health hackers' who are not waiting. BMC Med 2016;14:118.

99 Pearson JF, Brownstein CA, Brownstein JS. Potential for electronic health records and online social networking to redefine medical research. Clin Chem 2011;57:196-204.

100 Rivard L, Lehoux P, Alami H. "It's not just hacking for the sake of it": a qualitative study of health innovators' views on patient-driven open innovations, quality and safety. BMJ Qual Saf 2021;30:731-8.

101 Rundle CW, Dellavalle RP. PatientsLikeMe and atopic dermatitis: characterizing the atopic dermatitis patient profile. Dermatol Online J 2018;24:13030/qt70k8c9jn.

102 Sahama T, Liang J, lannella R. Impact of the social networking applications for health information management for patients and physicians. Stud Health Technol Inform 2012;180:803-7.

103 Smith CA, Wicks PJ. PatientsLikeMe: consumer health vocabulary as a folksonomy. AMIA Annual Symposium proceedings AMIA Symposium, 2008:682-6-6.

104 Trevena LJ. PatientsLikeMe and the tale of three brothers. Med J Aust 2011;195:258-9.

105 White K, Gebremariam A, Lewis D, et al. Motivations for participation in an online social media community for diabetes. $J$ Diabetes Sci Technol 2018;12:712-8.

106 Wicks P. Could digital patient communities be the launch pad for patient-centric trial design? Trials 2014;15:172.

107 Wicks P. Patient, study thyself. BMC Med 2018;16:217

108 Wicks P, Heywood JA. Data donation could power the learning health care system, including special access programs. Am J Bioeth 2014;14:27-9.

109 Wicks P, Keininger DL, Massagli MP, et al. Perceived benefits of sharing health data between people with epilepsy on an online platform. Epilepsy Behav 2012;23:16-23.

110 Wicks P, Massagli M, Frost J, et al. Sharing health data for better outcomes on PatientsLikeMe. J Med Internet Res 2010;12:e19-e.

111 Wicks P, Sulham KA, Gnanasakthy A. Quality of life in organ transplant recipients participating in an online transplant community. Patient 2014;7:73-84.

112 Wicks P, Vaughan T, Heywood J. Subjects no more: what happens when trial participants realize they hold the power? BMJ 2014;348:g368.

113 Williams III DS. The PatientsLikeMe ${ }^{\circledR}$ Multiple Sclerosis Community: Using online marketing to shift the health data privacy paradigm. J Commun Healthc 2010;3:48-61.

114 Demonaco $\mathrm{H}$, Oliveira P, Torrance A. When patients become Innovators. Mit Sloan Manage Rev 2019;60:81.

115 Kesavadev J, Srinivasan S, Saboo B, et al. The do-it-yourself artificial pancreas: a comprehensive review. Diabetes Ther 2020;11:1217-35. 